\title{
STUDY OF SEVERITY OF HYPONATRAEMIA AND ITS CLINICAL OUTCOME IN PATIENTS ADMITTED TO TERTIARY CARE ICU
}

\author{
Hareesh Rangaswamaiah1, Jayakumar Siddaraju2, Rajdeepak Valagerahalli Shivaraju3, Ashok Kumar Redrouthu4, \\ Mohammed Zia Ur Rahaman ${ }^{5}$ \\ ${ }^{1}$ Associate Professor, Department of Medicine, Dr. B. R. Ambedkar Medical College and Hospital, KG Halli, Bangalore. \\ ${ }^{2}$ Assistant Professor, Department of Medicine, Dr. B. R. Ambedkar Medical College and Hospital, KG Halli, Bangalore. \\ 3Junior Resident, Department of Medicine, Dr. B. R. Ambedkar Medical College and Hospital, KG Halli, Bangalore. \\ ${ }^{4} J$ unior Resident, Department of Medicine, Dr. B. R. Ambedkar Medical College and Hospital, KG Halli, Bangalore. \\ 5ICU Resident, Mediscope Hospital, Bangalore.
}

\section{ABSTRACT}

\section{BACKGROUND OF THE STUDY}

Hyponatraemia is a commonly encountered plasma electrolyte abnormality noticed in the patients admitted to ICU, which has a diverse variety of manifestations. It can lead to a wide spectrum of clinical symptoms, from subtle to severe or even life-threatening and is associated with increased mortality and morbidity.

\section{OBJECTIVES}

To study the clinical profile at different levels of hyponatraemia in ICU patients and its clinical outcome at different levels.

\section{METHODOLOGY}

A retrospective descriptional study was done at Intensive Care Unit of Dr. B.R. Ambedkar Medical College and Hospital during the period from April 2015 to March 2016 among the patients having serum sodium levels less than $135 \mathrm{mEq} / \mathrm{L}$.

\section{RESULTS}

Commonly involved age group is between 50 to 70 years. Severe form of Hyponatraemia is seen in elderly males. The most common underlying predisposing factor for hyponatraemia in our case series was sepsis (26\%) followed by gastrointestinal fluid loss $(15.5 \%)$, diabetic ketoacidosis $(10 \%)$ and cirrhosis of liver (10\%). Mortality was highest with severe hyponatraemia (10.5\%) who had pulmonary sepsis, metabolic encephalopathy, diabetic ketoacidosis and cirrhosis of liver.

\section{CONCLUSIONS}

Hyponatraemia is one of the good predictor of ICU mortality in association with wide variety of systemic diseases and wide spectrum of clinical profile.

\section{KEYWORDS}

Hyponatraemia, Serum Sodium Levels, ICU.

HOW TO CITE THIS ARTICLE: Rangaswamaiah H, Siddaraju J, Shivaraju RV, et al. Study of severity of hyponatraemia and its clinical outcome in patients admitted to tertiary care ICU. J. Evolution Med. Dent. Sci. 2016;5(49):3122-3126, DOI: $10.14260 /$ jemds/2016/725

\section{INTRODUCTION}

Disorders of serum $\mathrm{Na}^{+}$concentration are caused by abnormalities in water homeostasis that lead to changes in the relative ratio of $\mathrm{Na}^{+}$to body water. Water intake and circulating AVP constitute the two key effectors in the defense of serum osmolality; defects in one or both of these defense mechanisms cause most cases of hyponatraemia and hypernatremia. Hyponatraemia, which is defined as a plasma $\mathrm{Na}^{+}$concentration $<135 \mathrm{~mm}$ is a very common disorder, occurring in up to $22 \%$ of hospitalized patients. This disorder is almost always the result of an increase in circulating AVP and/or increased renal sensitivity to AVP, combined with any intake of free water; a notable exception is hyponatraemia due to low solute intake. 1

Financial or Other, Competing Interest: None.

Submission 20-05-2016, Peer Review 01-06-2016,

Acceptance 03-06-2016, Published 17-06-2016.

Corresponding Author:

Dr. Hareesh Rangaswamaiah,

Associate Professor

Department of General Medicine,

Dr. B. R. Ambedkar Medical College and Hospital,

KG Halli, Bangalore-560045.

E-mail: hareesh22578@gmail.com

DOI: $10.14260 /$ jemds $/ 2016 / 725$
Despite the awareness on hyponatraemia since mid-20 th century, this common disorder is still incompletely understood in many basic areas due to its association with a wide range of underlying disease states multiple aetiologies and differing pathophysiological mechanisms. ${ }^{2}$ Hyponatraemia can be classified according to the volume status of the patient as Hypovolemic, Hypervolemic or Euvolemic. ${ }^{1,3}$ Hypervolemic Hyponatraemia may be caused by congestive cardiac failure, liver cirrhosis and renal disease. ${ }^{3}$

Acute symptomatic hyponatraemia is a medical emergency that occurs in a number of specific settings. 1. Iatrogenic: Postoperative: Premenopausal women, hypotonic fluids with cause of increased vasopressin, glycine irrigation; TURP, uterine surgery, colonoscopy preparation, recent institution of thiazides; 2. Polydipsia; 3. MDMA ingestion; 4. Exerciseinduced; 5. Multifactorial, e.g. thiazide and polydipsia. ${ }^{1}$

The symptoms of hyponatraemia are primarily neurologic, reflecting the development of cerebral oedema within a rigid skull. The initial CNS response to acute hyponatraemia is an increase in interstitial pressure, leading to shunting of ECF and solutes from the interstitial space into the cerebrospinal fluid and then into the systemic circulation. ${ }^{1}$ The clinical presentation has a wide spectrum varying from asymptomatic patients to ones having seizures and coma. ${ }^{4,5}$ 
Early symptoms can include nausea, headache and vomiting. However, severe complications can evolve rapidly including seizure activity, brainstem herniation, coma and death. A key complication of acute hyponatraemia is normocapnic or hypercapnic respiratory failure; the associated hypoxaemia may amplify the neurologic injury. ${ }^{1}$ In chronic hyponatraemia cerebral adaptation helps the patient to be asymptomatic, though the plasma sodium is as low as $115-120 \mathrm{mEq} / \mathrm{L}$. Clinically, hyponatraemia is often unrecognized when it is mild or when it develops slowly.

But severe hyponatraemia (plasma sodium $<120 \mathrm{mmol} / \mathrm{l}$ ), particularly of rapid onset is associated with substantial morbidity and can be life-threatening. Also moderate-tosevere hyponatraemia bears a substantial associated morbidity and mortality.6,7,8 It is known that hyponatraemia is associated with longer hospital days, medical costs and higher mortality compared to eunatremia.9,10 Although, it is hypothesized that long-term hyponatraemia might disturb the metabolic and genetic balance in cells, resulting in higher mortality, pathophysiologic effect of hyponatraemia on clinical outcome has not yet clearly been identified. ${ }^{11}$

Acute or symptomatic hyponatraemia can lead to significant rates of morbidity and mortality.12,13 Mortality rates as high as $17.9 \%$ have been quoted, but this extreme rate usually occurs in the context of hospitalized ICU patients. ${ }^{3,14}$ Morbidity also can result from rapid correction of hyponatraemia. ${ }^{3}$

Treatment was individualized. Overtly symptomatic patients were treated with hypertonic saline intravenously by proper dose and rate calculation followed by oral salt supplementation. ${ }^{4}$ Evaluation of other disease associated with the hyponatraemia is vital, as they are involved in the pathogenesis of the disease. Hence, the physician should have suspicion of hyponatraemia in patients with pneumonia, pulmonary tuberculosis, pulmonary abscess, bronchiectasis, malignancies and chronic obstructive pulmonary disease. ${ }^{15,16}$ Data regarding the incidence of hyponatraemia in our country is limited. This study was done to know the common clinical features and aetiology of hyponatraemia in hospitalized (ICU) patients and to correlate the outcome of these patients with admission serum sodium levels.

\section{MATERIALS AND METHODS}

This retrospective descriptional study was conducted from April 2015 to March 2016 in ICU of Dr. B.R. Ambedkar Medical College and Hospital, Bangalore. Patients with serum sodium levels less than $135 \mathrm{mEq} / \mathrm{L}$ at the time of admission with or without symptoms of hyponatraemia were selected and treated with 3\% saline (Hypertonic saline) according to severity of symptoms and serum sodium levels. Patients with age group below 18 years and above 80 years and severe renal dysfunction and post-operative patients were excluded from the study. Data was collected retrospectively from all the patients with hyponatraemia fulfilling the Inclusion and Exclusion Criteria. Excel and SPSS software packages were used for data entry and analysis.

\section{RESULTS}

This study clinical data was taken retrospectively from ICU patients of a tertiary care hospital from April 2015 to March 2016. The total number of admissions to ICU during the above period was 708 patients. Compared to other electrolyte disturbances, we found that hyponatraemia on admission was most prevalent.

Out of them 200 patients (28.25\%) had Serum Sodium levels $<135 \mathrm{mEq} / \mathrm{L}$. There were $123(61.5 \%)$ male patients and 77 (38.5\%) female patients. [Figure 1]

\section{Age- Sex Distribution}

123 male patients and 77 female patients.

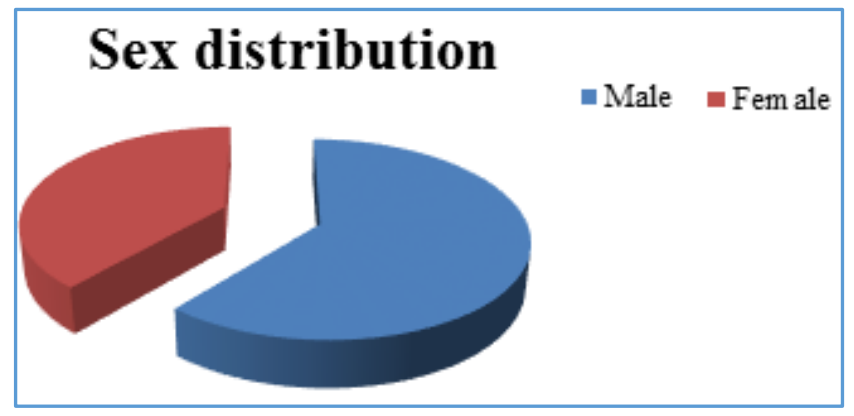

Fig. 1: Age-Sex Distribution

Commonly involved age group was between 51 to 70 years.

Mild and Moderate hyponatraemia was common in age group between 51 to 60 years [Figure 2], whereas severe hyponatraemia was common between the age group of 61 to 70 years [Figure 3].

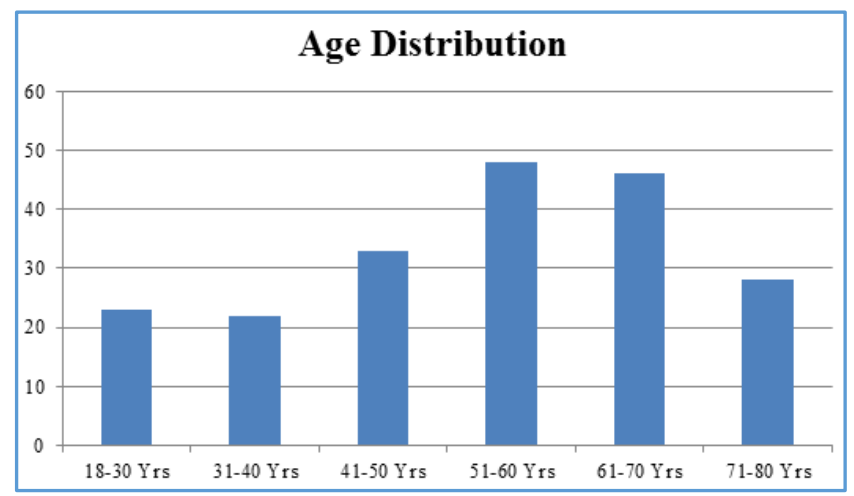

Fig. 2: Age Distribution Comparison

\begin{tabular}{|c|c|}
\hline Age Distribution & No. of Patients \\
\hline 18-30 Yrs. & 23 \\
\hline 31-40 Yrs. & 22 \\
\hline $41-50$ Yrs. & 33 \\
\hline 51-60 Yrs. & 48 \\
\hline $61-70$ Yrs. & 46 \\
\hline 71-80 Yrs. & 28 \\
\hline
\end{tabular}

\begin{tabular}{|c|c|c|}
\hline $\begin{array}{c}\text { Age } \\
\text { Distribution }\end{array}$ & $\begin{array}{c}\text { Mild and } \\
\text { Moderate }\end{array}$ & $\begin{array}{c}\text { Severe } \\
\text { Hyponatraemia }\end{array}$ \\
\hline 18-30 Yrs. & 16 & 7 \\
\hline $31-40$ Yrs. & 16 & 6 \\
\hline $41-50$ Yrs. & 24 & 9 \\
\hline 51-60 Yrs. & 31 & 17 \\
\hline $61-70$ Yrs. & 26 & 20 \\
\hline $71-80$ Yrs. & 15 & 13 \\
\hline
\end{tabular}




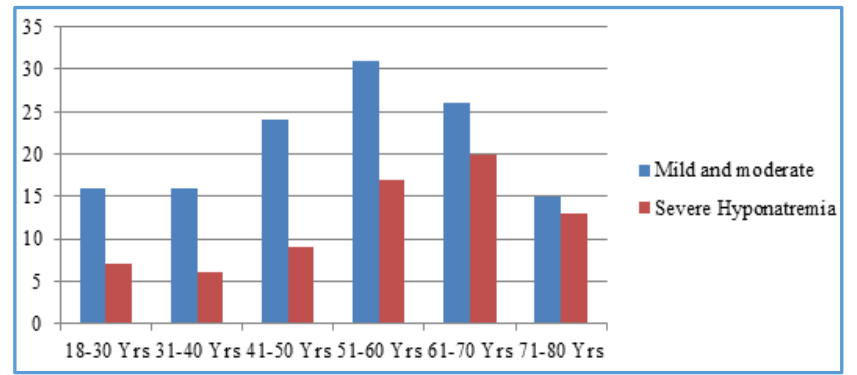

Fig. 3: Age Distribution Comparison

Severe hyponatraemia was detected in $72(36 \%)$ patients. Mild hyponatraemia and moderate hyponatraemia was seen in $65(32.5 \%)$ and $63(31.5 \%)$ patients respectively. Severe hyponatraemia was commonly seen in patients with sepsis 36 (50\%), metabolic encephalopathy $26(34.72 \%)$, cirrhosis of liver $6(8.33 \%)$ and diabetic ketoacidosis 5 (6.9\%).

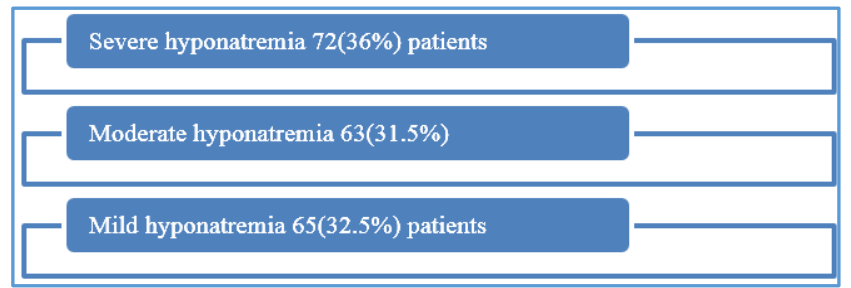

The most common underlying predisposing factor for hyponatraemia in our case series was sepsis (26\%) followed by gastrointestinal fluid loss (15.5\%), diabetic ketoacidosis $(10 \%)$ and cirrhosis of liver (10\%). Other causes of hyponatraemia were cerebrovascular accidents (9\%), meningitis (5\%), acute pancreatitis $(4.5 \%)$, viral fever (3\%), chronic obstructive pulmonary disease $(2.5 \%)$ and hypertensive encephalopathy (1\%) [Figure 4].

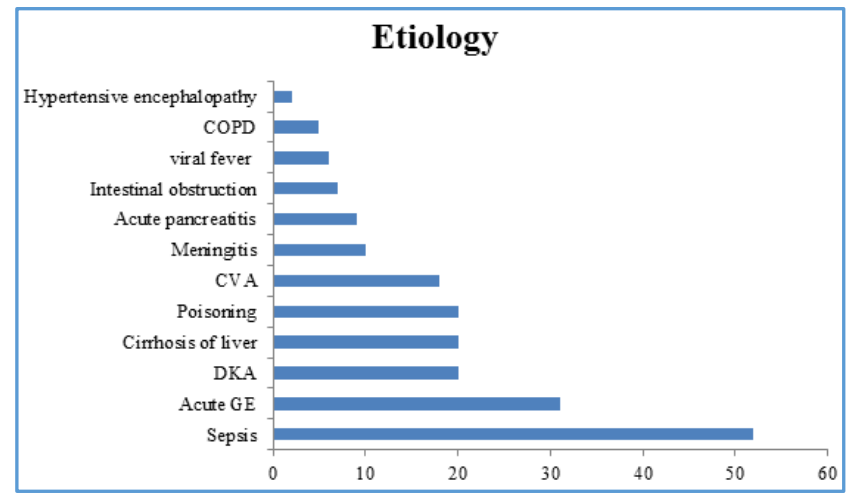

Fig. 4: Aetiological Distribution of Hyponatraemic Patients

\begin{tabular}{|c|c|}
\hline & Aetiology \\
\hline Sepsis & $52(26 \%)$ \\
\hline Acute GE & $31(15.5 \%)$ \\
\hline DKA & $20(10 \%)$ \\
\hline Cirrhosis of liver & $20(10 \%)$ \\
\hline Poisoning & $20(10 \%)$ \\
\hline CVA & $18(9 \%)$ \\
\hline Meningitis & $10(5 \%)$ \\
\hline Acute pancreatitis & $9(4.5 \%)$ \\
\hline Intestinal obstruction & $7(3.5 \%)$ \\
\hline viral fever & $6(3 \%)$ \\
\hline COPD & $5(2.5 \%)$ \\
\hline Hypertensive encephalopathy & $2(1 \%)$ \\
\hline
\end{tabular}

\section{Clinical Profile Comparison}

The major symptoms seen in mild and moderate hyponatraemia were nausea and dyspnoea, whereas altered sensorium and seizures were common in severe hyponatraemia.

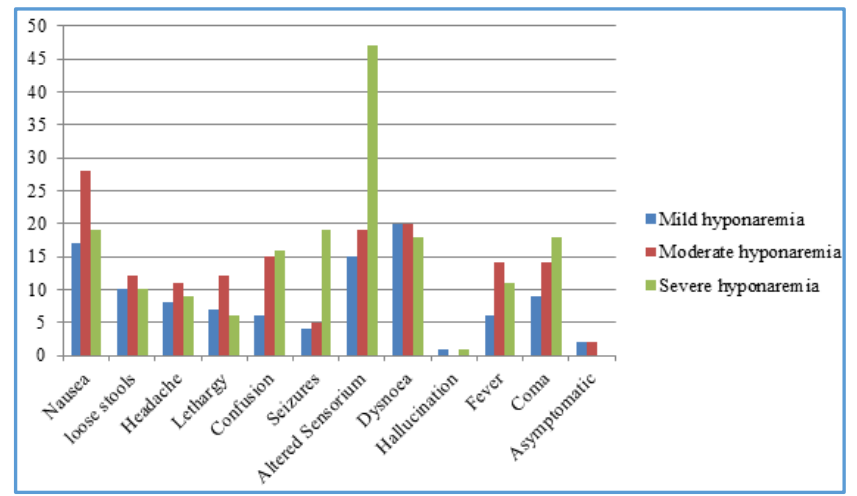

Fig. 5: Clinical Profile of Hyponatraemia

\begin{tabular}{|c|c|c|c|}
\hline Symptoms & $\begin{array}{c}\text { Mild Hypo- } \\
\text { natraemia }\end{array}$ & $\begin{array}{c}\text { Moderate } \\
\text { Hypo- } \\
\text { natraemia }\end{array}$ & $\begin{array}{c}\text { Severe } \\
\text { Hypo- } \\
\text { natraemia }\end{array}$ \\
\hline Nausea & 17 & 28 & 19 \\
\hline $\begin{array}{c}\text { Loose } \\
\text { stools }\end{array}$ & 10 & 12 & 10 \\
\hline Headache & 8 & 11 & 9 \\
\hline Lethargy & 7 & 12 & 6 \\
\hline Confusion & 6 & 15 & 16 \\
\hline Seizures & 4 & 5 & 19 \\
\hline $\begin{array}{c}\text { Altered } \\
\text { Sensorium }\end{array}$ & 15 & 19 & 47 \\
\hline Dyspnoea & 20 & 20 & 18 \\
\hline $\begin{array}{c}\text { Hallucinati } \\
\text { on }\end{array}$ & 1 & 0 & 1 \\
\hline Fever & 6 & 14 & 11 \\
\hline Coma & 9 & 14 & 18 \\
\hline $\begin{array}{c}\text { Asymptom } \\
\text { atic }\end{array}$ & 2 & 2 & 0 \\
\hline \multicolumn{2}{|c|}{} & & \\
\hline
\end{tabular}

Associated Comorbid Conditions (Diabetes, Hypertension, etc.) in Hyponatraemia

Out of 200 patients with hyponatraemia, 141 patients $(70.5 \%)$ had co-morbid conditions like diabetes mellitus (35\%), hypertension $(28.5 \%)$, renal failure $(2 \%)$ and ischaemic heart disease (5\%) [Figure 6].

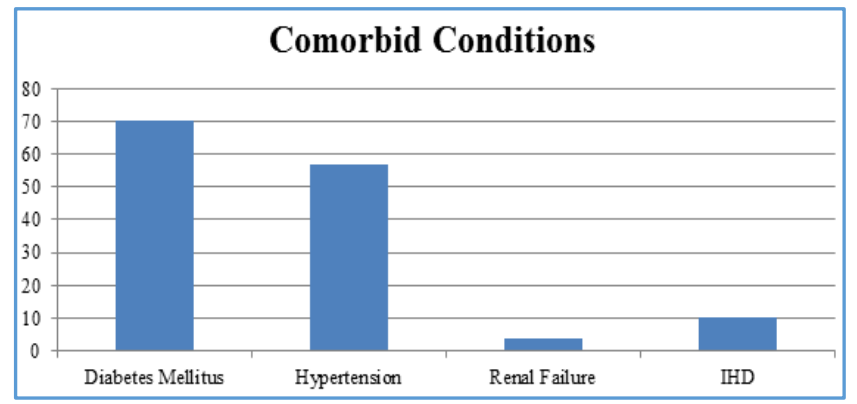

Fig. 6: Associated Co-Morbid Conditions in Hyponatraemic Patients 


\section{Outcome}

Among 200 patients with hyponatraemia, 174 patients were improved and 26 patients died during the course of treatment. Mortality was highest with severe hyponatraemia patients (10.5\%) who had sepsis, metabolic encephalopathy, cirrhosis of liver and diabetic ketoacidosis.
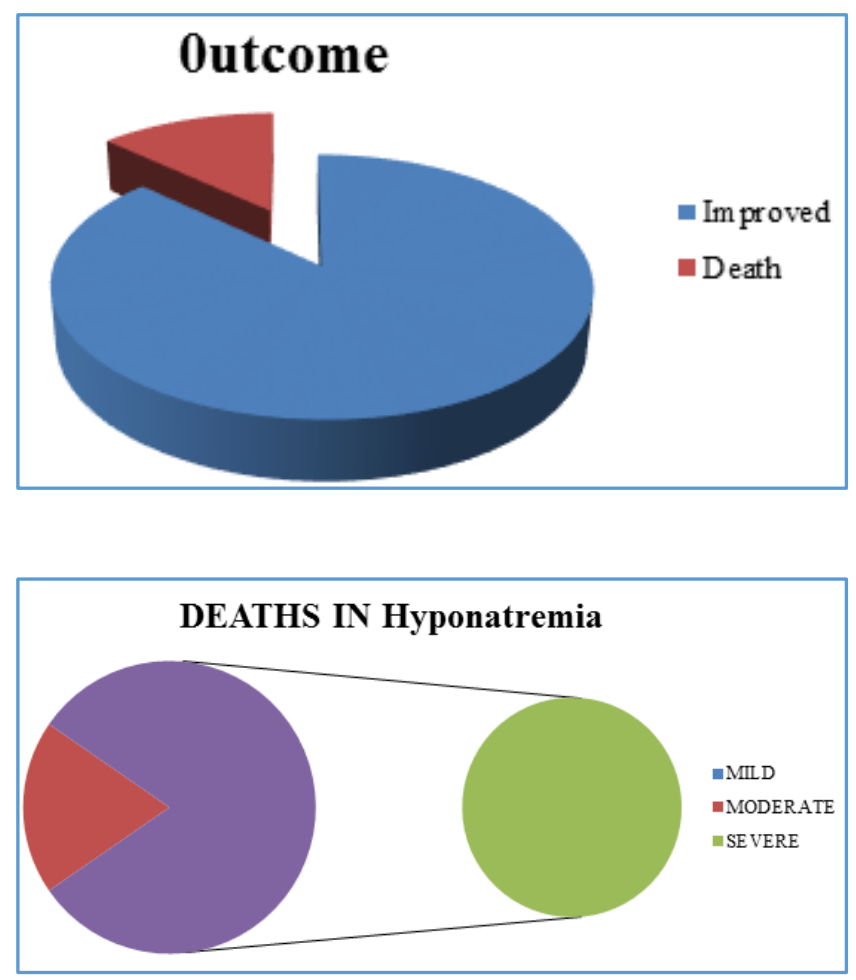

\section{DISCUSSION}

Hyponatraemia is associated with substantial morbidity and mortality. The identification of risk factors associated with the development of symptomatic hyponatraemia is important in determining preventive strategies. The occurrence of severe hyponatraemia seen in elderly sick patients with other multiple co-morbidities was found to be $28 \%$. In other studies like Chatterji et al, the incidence was $16.4 \%$ and in Pandey and Pandey et al it was $9 \% .{ }^{17}$ In our study, $61.5 \%$ were males and $38.5 \%$ were females which was similar in other studies like pandey and pandey et al (Males: 65\%, Females: 35\%). ${ }^{17}$ and Agarwal and Agrawal et al (Males: 64.3\%, Females: 35.7\%). ${ }^{18}$ The commonly involved age group was between 51 to 70 years in our study. Mild and moderate hyponatraemia was common in age group between 51 to 60 years, whereas severe hypontraemia was common in age group between 61 to 70 years. The population predominantly belonged to the age groups 51 to 70 years in a study done by Paniker and Joseph et al and it was 60 to 80 years in Chatterji et al.

Confusion followed by altered sensorium were major symptoms in patients with severe hyponatraemia in Agarwal and Agarwal et al. ${ }^{18}$ But, in our study, altered sensorium followed by seizures were the major symptoms.

Analysis of the causes of hyponatraemia in our patients revealed that most patients had multiple predisposing factors. The most common underlying predisposing factor for hyponatraemia in our case series was sepsis (26\%) followed by gastrointestinal fluid loss (15.5\%) followed by Diabetic ketoacidosis $(10 \%)$ and cirrhosis of liver $(10 \%)$. In a study done by Panikar and Joseph et al, the incidence of congestive heart failure was $24 \%$ which was the most common cause of hyponatraemia followed by gastrointestinal loss (18\%) and cirrhosis of liver (7\%). Analysis of the causes of hyponatraemia in study done by Agarwal and Agrawal et al revealed that most patients (94.3\%) had multiple precipitating factors. Increased loss of sodium from the body was seen in $65.7 \%$ patients, most commonly via gastrointestinal route. Volume overload due to cardiac, renal and hepatic disease was a factor in $48 \%$ patients.

Diuretics as a precipitating factor for hyponatraemia was found in $37.1 \%$ of patients in this study. ${ }^{18}$ In a study done by Chateerji et al, gastrointestinal fluid loss, cerebrovascular accident and pulmonary sepsis were the most frequent predisposing risk factors.

Among 200 Hyponatraemic patients, mortality was seen with severe form of hyponatraemia (10.5\%) followed by moderate hyponatraemia $(2.5 \%)$. This above mortality correlates with comorbid diseases like sepsis, metabolic encephalopathy, cirrhosis of liver and diabetic ketoacidosis. Most of the patients in our study had multiple underlying diseases like sepsis, gastrointestinal loss of fluids, cerebrovascular accidents with hypertensive encephalopathy, cirrhosis of liver, diabetic ketoacidosis, neuro-infections, chronic obstructive pulmonary disease, acute febrile illness and congestive heart failure.

\section{CONCLUSION}

Hyponatraemia must be actively looked for and corrected early, as delay in starting treatment worsens the hyponatraemia and prolongs the hospital stay. The severity of symptoms and signs are generally more prominent in elderly patients due to their failure of homeostatic mechanisms. It is also important to evaluate the aetiology of hyponatraemia, so that specific underlying cause can be treated. The mortality depends not only with severity of hyponatraemia even with underlying diseases, and also patient's presenting symptoms like confusion, altered sensorium, seizures and coma. So that serum sodium levels and clinical profile are the good predictors of mortality.

\section{REFERENCES}

1. Mount DB. Fluid and electrolyte disturbances, Harrison's principles of internal medicine. 19th edition. McGraw-Hill Professional chapter 63, p295-301.

2. Verbalis JG. The syndrome of inappropriate antidiuretic hormone secretion and other hupoosmolar disorders. In: Schrier RW, ed. Disease of the kidney and urinary tract. Philadelphia, Pa: Lippincott Williams and Wilkins 2007;2214-48.

3. Ranadip Chowdhury, Tanmay Samanta, Koushik Pan, et al. Can hyponatraemia predict mortality in intensive care unit patients: a prospective study in a tertiary care hospital in Kolkata. Int J Med Pharm Sci 2013;3(7):26-30.

4. Chatterji N, Sengupta N, Das C, et al. A descriptive study of hyponatraemia in a tertiary care hospital of eastern India. IJEM 2012;16(2):288-91.

5. Laczi F. Aetiology, diagnostics, and therapy of hyponatraemias. Orv Hetil 2008;149(29):1347-54.

6. Paniker GI, Joseph S. A prospective study on clinical profile of hyponatraemia in ICU hospitalized patients. IJBAR 2014;5(6):298-303. 
7. Arieff Al. Hyponatraemia convulsions, respiratory arrest, and permanent brain damage after elective surgery in healthy women. New England Journal of Medicine 1986;314:1529-35.

8. Anderson RJ. Hospital-acquired hyponatraemia. Kidney International 1986;29:1237-47.

9. Upadhyay A, Jaber BL, Madias NE. Epidemiology of hyponatraemia. Semin Nephrol 2009;29(3):227-38.

10. Zilberberg MD, Exuzides A, Spalding J, et al. Epidemiology, clinical and economic outcomes of admission hyponatraemia among hospitalized patients. Curr Med Res Opin 2008;24(6):1601-8.

11. Doshi SM, Shah P, Lei $X$, et al. Hyponatraemia in hospitalized cancer patients and its impact on clinical outcomes. Am J Kidney Dis 2012;59(2):222-8.

12. Raynolds RM, Padfield PL, Seckl JR. Disorder of sodium balance. BMJ 2006;332:702-5.

13. Huda MS, Boyd A, Skagen K, et al. Investigation \& management of severe hyponatraemia in hospital setting. Postgrad Med J 2006;82(965):216-9.
14. Callahan MA, Do HT, Caplan DW, et al. Economic impact of hyponatraemia in hospitalized patients: a retrospective cohort study. Postgrad Med 2009;121(2):186-91.

15. Bartter FC, Schwartz WB. The syndrome of inappropriate secretion of antidiuretic hormone. Am J Med 1967;42(5):790-806.

16. Miller M, Morley JE, Rubenstein LZ. Hyponatraemia in a nursing home population. J Am Geriatr Soc 1995;43(12):1410-3.

17. Sushma Pandey, Suresh Pandey. Hyponatraemia in a tertiary care hospital of Rajasthan: an observational study. Int J Sci study 2015;2(12):5-7.

18. Mahavir Agarwal S, Aparna Agrawal. A comparative study of the clinic-aetiological profile of hyponatraemia at presentation with that developing in the hospital. Indian J Med Res 2011;134:118-22. 